\title{
Alkaline Activation of Kaolin Group Minerals
}

\author{
Oliwia Biel, Piotr Rożek *(D), Paulina Florek ${ }^{\mathbb{D}}$, Włodzimierz Mozgawa and Magdalena Król(D) \\ Faculty of Materials Science and Ceramic, AGH University of Science and Technology, 30 Mickiewicza Av., \\ 30-059 Krakow, Poland; oliwia.biel@gmail.com (O.B.); paulina@agh.edu.pl (P.F.); mozgawa@agh.edu.pl (W.M.); \\ mkrol@agh.edu.pl (M.K.) \\ * Correspondence: prozek@agh.edu.pl
}

Received: 2 March 2020; Accepted: 31 March 2020; Published: 2 April 2020

\begin{abstract}
Zeolites can be obtained in the process of the alkali-activation of aluminosilicate precursors. Such zeolite-geopolymer hybrid bulk materials merge the advantageous properties of both zeolites and geopolymers. In the present study, the effect of the type and concentration of an activator on the structure and properties of alkali-activated metakaolin, and metahalloysite was assessed. These two different kaolinite clays were obtained by the calcination of kaolin and halloysite, and then activated with sodium hydroxide and water glass. The phase compositions were assessed by X-ray diffraction, the microstructure was observed via scanning electron microscope, and the structural studies were conducted on the basis of the infrared spectra. The structure and properties of the obtained alkali-activated materials depend on both the type of a precursor and the type of an activator. The formation of zeolite phases was observed when the activation was carried out with sodium hydroxide alone, or with a small addition of water glass, regardless of the starting material used. The higher proportion of silicon in the activator solution does not give crystalline phases, but only an amorphous phase. Geopolymers based on metahalloysite have better compressive strength as the result of the better reactivity of metahalloysite compared to metakaolin.
\end{abstract}

Keywords: zeolite; alkali-activation; geopolymer; metakaolin; metahalloysite

\section{Introduction}

Zeolites are crystalline aluminosilicates (having the general chemical formula $\mathrm{Me}_{2 / \mathrm{n}} \mathrm{O} \cdot \mathrm{Al}_{2} \mathrm{O}_{3} \cdot \mathrm{xSiO}_{2} \cdot \mathrm{yH}_{2} \mathrm{O}$ [1], with the possibility of $\left[\mathrm{SiO}_{4}\right]$ substitution by another elements, e.g., $\left.\left[\mathrm{PO}_{4}\right]\right)$ whose characteristic feature is the microporous, regular structure with a constant channel and pore size. This feature is an advantage of zeolites over other known sorbents, as it enables the selective adsorption of ions and molecules. Zeolites are one of the products of alkali-activated aluminosilicate precursors. The activation is conducted by treating the material with an alkaline solution, and keeping for an appropriate time at an elevated temperature. This method of obtaining zeolites is well known, and has been used since many years; however, an improvement of its parameters is still the subject of research [2]. Depending on the used parameters, geopolymer gel and zeolites can be found among the reaction products. That type of composite is known as a zeolite-geopolymer hybrid bulk material.

Zeolite-geopolymer hybrid bulk materials are composites that combine the advantages of zeolites as a dispersed phase and geopolymer as a matrix. Their structure contains the meso-porosity of the geopolymer and the micro-porosity of the zeolite [3]. The range of porosity in those materials is very wide, and reaches from $5 \AA$ up to $2 \mu \mathrm{m}$ [4]. It was proven [3] that there is a relationship between the properties of initial kaolinite, its meta phase and the final product: zeolite-geopolymer hybrid bulk material, which gives opportunity to adjust the contents of desirable phases, and in consequence, the range of porosity.

There are known various aluminosilicate precursors, such as synthetic ones (coal fly ash, ash from waste incineration, blast furnace slag, etc.) or natural clays, for instance, kaolinite and 
halloysite. Using those natural minerals for the synthesis of zeolite and zeolite-geopolymer hybrid bulk materials is a topical issue $[3,5,6]$. Despite the fact that both kaolinite $\left(\mathrm{Al}_{2} \mathrm{Si}_{2} \mathrm{O}_{5}(\mathrm{OH})_{4}\right)$ and halloysite $\left(\mathrm{Al}_{2} \mathrm{Si}_{2} \mathrm{O}_{5}(\mathrm{OH})_{4} \cdot 2 \mathrm{H}_{2} \mathrm{O}\right)$ have similar compositions [7], their reactivity is different. The source of the differences is the presence of interlayer water in halloysite's structure, which results in its greater porosity, chemical activity and specific surface area [8].

In this work, the results of the structural studies of different composites, obtained using the alkali-activation method and two different kaolinite clays as starting materials, were presented. It is well known that kaolinite and halloysite change into hydroxysodalite by the treatment with sodium hydroxide. It is also known that sodium zeolite type A can be synthesized from both raw materials [9-11]. However, the methodology for preparing composites varies in all available works. Therefore, the aim of this work was to compare the impact of the raw material structure on the course of the synthesis process. As activators, $\mathrm{NaOH}$ and water glass were applied. The specific objectives were to compare the properties of materials obtained on the basis of metakaolin and metahalloysite, their structural characterization, and the assessment of the impact of the activator type on the properties and structure of the resulting zeolite-geopolymer hybrid bulk materials. Such composites would possess the synergistic benefits of both zeolites and geopolymers, and could be used as monolithic sorbents, self-supported zeolite sieves or membranes, rather than construction materials.

\section{Materials and Methods}

\subsection{Chemicals}

Clays from two different Polish deposits were used in this study: kaolin from the Maria III (KSM Surmin-Kaolin S.A., Nowogrodziec, Poland) and halloysite from the Dunin (Kopalnia Haloizytu DUNINO Sp. z o. o., Krotoszyce, Poland). Sodium hydroxide (analytically pure $\mathrm{NaOH}$ as microbeads) and water glass (the content of $\mathrm{Na}_{2} \mathrm{O} 11.4 \mathrm{wt} . \%$ and $\mathrm{SiO}_{2} 27.6 \mathrm{wt} . \%$ ) were used as the activator.

\subsection{Pre-Treatment of Natural Clays}

The homogenized samples of kaolin and halloysite were thermally treated at $700{ }^{\circ} \mathrm{C}$ for $2 \mathrm{~h}$ (the temperature was chosen on the basis of the previous work [12]), in order to obtain more reactive materials, metakaolin and metahalloysite.

\subsection{Alkali-Activation}

The alkali-activated paste samples were synthesized using $4 \mathrm{~mL}$ of the activator per $5 \mathrm{~g}$ of metakaolin. The compositions of the specimens are summarized in Table 1. The solid and solution were mechanically stirred for several minutes at room temperature. The fresh paste was poured into a silicone mold ( $20 \mathrm{~mm} \times 20 \mathrm{~mm} \times 20 \mathrm{~mm}$ cubic samples) and activated at $80^{\circ} \mathrm{C}$ for $24 \mathrm{~h}$. After this time, the samples were demolded and left to mature for another 27 days. With each mixture at least eight samples were prepared.

Table 1. The mixture proportions of geopolymer pastes and their molar ratios of silica, alumina, water and sodium oxide.

\begin{tabular}{|c|c|c|c|c|c|c|}
\hline Sample Name & MK/MH [g] & $8 \mathrm{M} \mathrm{NaOH}[\mathrm{mL}]$ & Water Glass [mL] & $\mathrm{SiO}_{2} / \mathrm{Al}_{2} \mathrm{O}_{3}$ & $\mathrm{Na}_{2} \mathrm{O} / \mathrm{Al}_{2} \mathrm{O}_{3}$ & $\mathrm{H}_{2} \mathrm{O} / \mathrm{Na}_{2} \mathrm{O}$ \\
\hline MK1/MH1 & 1.00 & 0.80 & 0.00 & $2.1 / 2.1$ & $0.7 / 0.9$ & $13.2 / 13.0$ \\
\hline MK2/MH2 & 1.00 & 0.70 & 0.10 & $2.2 / 2.3$ & $0.7 / 0.9$ & $13.7 / 13.5$ \\
\hline MK3/MH3 & 1.00 & 0.60 & 0.20 & $2.4 / 2.5$ & $0.7 / 0.9$ & $14.2 / 13.9$ \\
\hline MK4/MH4 & 1.00 & 0.50 & 0.30 & $2.6 / 2.7$ & $0.7 / 0.9$ & $14.7 / 14.4$ \\
\hline MK5/MH5 & 1.00 & 0.40 & 0.40 & $2.7 / 2.9$ & $0.7 / 0.9$ & $15.3 / 15.0$ \\
\hline
\end{tabular}




\subsection{Characterization}

The solid-state characterization techniques, such as X-Ray Fluorescence (XRF), X-Ray Diffraction (XRD), Infrared Spectroscopy (FT-IR) and Scanning Electron Microscopy (SEM), were carried out on both raw materials, and on the as-synthesized materials.

The chemical compositions of the starting materials were determined using $X$-ray fluorescence. The spectrum was detected using the wavelength dispersive $X$-ray fluorescence spectrometer (WD-XRF) Axios mAX 4 kW, PANalytical equipped with Rh source. The PANalytical standardless analysis package Omnian was used for the quantitative analysis of the spectra.

The resulting materials were analyzed in the terms of the phase composition by means of Philips $\mathrm{X}$-ray powder diffraction $\mathrm{X}^{\prime} \mathrm{P}$-ert system $\left(\mathrm{CuK}_{\alpha}\right.$ radiation). The measurements were carried out in the $2 \theta$ angle range of $5-90^{\circ}$ for $2 \mathrm{~h}$, with a step of 0.007 . Phases were identified with the use of an $X^{\prime}$ Pert HighScore Plus application, and the International Centre for Diffraction Data.

The existence of zeolite frameworks was also confirmed by the analysis of the spectra in the mid infrared (4000-400 $\mathrm{cm}^{-1}$ ) that were measured on Bruker VERTEX 70v vacuum FT-IR spectrometer using the standard $\mathrm{KBr}$ pellets methods. They were collected in after 64 scans at $4 \mathrm{~cm}^{-1}$ resolution.

The microstructure of the resulting samples was observed using a scanning electron microscope FEI Nova NanoSEM 200. The samples were sprayed with graphite.

The bulk density was calculated by dividing the mass of the sample by its volume. The compressive strength of the samples, measured by using the ZwickRoell device machine that works on the principle of a hydraulic press, is defined as the ratio of the sample breaking force to the area on which the force acts. Eight similar samples were tested, and the average of the eight measurements was taken.

\section{Results and Discussion}

\subsection{Characterization of Raw Materials}

Both kaolinite and halloysite are considered to be the polytypical forms of aluminum monophyllosilicate with 1:1 packets [13]. They differ in the way the layer packages are arranged in the crystal structure [14]. The kaolinite crystals have a lamellar habit. The shifting of two layers relative to each other, tetrahedral $(\mathrm{Si}-\mathrm{O})$ and octahedral $(\mathrm{Al}-\mathrm{OH})$, creates a tubular halloysite structure. The characteristic feature of halloysite is also the presence of water molecules in the inter-package space. The presence of water causes an increase in the distance between the layer packs, where for halloysite it is $10.1 \AA$, while for kaolinite, this is $7.15 \AA$. Both minerals dehydroxylate at $600-800{ }^{\circ} \mathrm{C}$ [15]. As the products, more active amorphous metakaolin and metahalloysite, are obtained.

The chemical compositions of the obtained intermediates, determined on the basis of X-ray fluorescence spectrometry, are summarized in Table 2. By comparing both compositions, it can be stated that the metakaolin sample has a higher silica content, whereas halloysite has higher amounts of iron oxide. In addition, the molar ratio of the main components ( $\mathrm{Si} / \mathrm{Al})$ in both cases was about 2 . The content of $\mathrm{CaO}$ in both materials is below $1 \%$, so the resulting products can be called geopolymers (due to the limitation of this name to low-calcium alkali-activated materials).

Table 2. The chemical compositions of the metakaolin and metahalloysite.

\begin{tabular}{cccccccccc}
\hline $\begin{array}{c}\text { Chemical } \\
\text { Composition [wt.\%] }\end{array}$ & $\mathrm{SiO}_{2}$ & $\mathrm{TiO}_{2}$ & $\mathrm{Al}_{2} \mathrm{O}_{3}$ & $\mathrm{Fe}_{2} \mathrm{O}_{3}$ & $\mathbf{M g O}$ & $\mathrm{CaO}$ & $\mathbf{N a}_{2} \mathrm{O}$ & $\mathrm{K}_{\mathbf{2}} \mathrm{O}$ & Residual \\
\hline MK: metakaolin & 53.74 & 0.47 & 43.82 & 0.87 & 0.27 & 0.14 & 0.13 & 0.36 & 0.20 \\
MH: metahalloysite & 40.39 & 2.39 & 32.86 & 20.13 & 0.37 & 0.88 & 0.43 & 0.25 & 2.30 \\
\hline
\end{tabular}

Figure 1 shows the XRD-patterns of both clays ( $\mathbf{K}=$ kaolinite and $\mathbf{H}=$ halloysite) before and after the calcination. The XRD analysis of kaolin (Figure 1a) showed that it consisted of kaolinite and quartz. After the thermal treatment, only the peaks from quartz, which is not decomposed, are visible. The 
appearance of an amorphous "halo" in the $20-30^{\circ}$ range on the 2-theta scale indicates the distribution of kaolinite to the amorphous metakaolin.

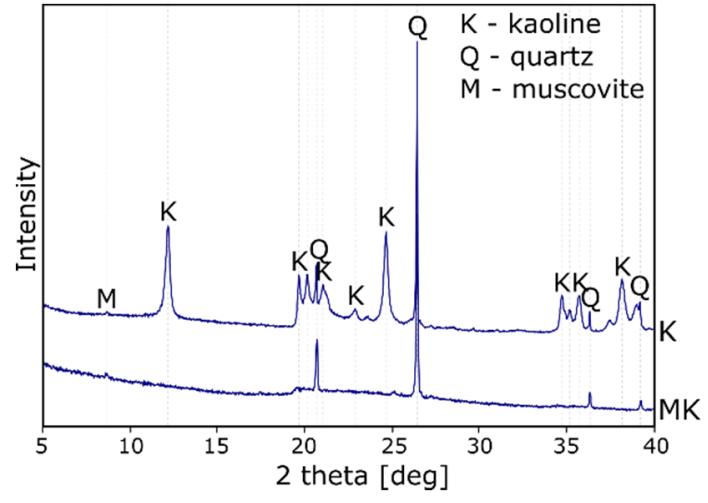

(a)

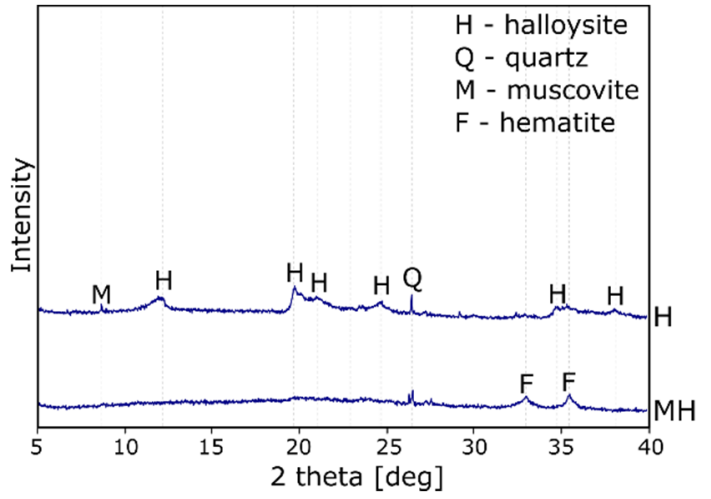

(b)

Figure 1. The X-ray diffractometry (XRD) patterns of initial clays and clays after the calcination at $700{ }^{\circ} \mathrm{C}$ : (a) kaolinite; (b) halloysite.

In turn, the analysis of the phase composition of halloysite (Figure 1b) showed that it included, in addition to halloysite, quartz and hematite. For both halloysite and metahalloysite, the reflections are wider, compared to the samples of kaolin and metakaolin, respectively, which indicates a greater defect or the smaller size of crystallites. In addition, the XRD pattern shows reflections from hematite, such that the high iron content in the chemical composition (Table 2) confirms its presence; and it also gave the material a brown color. Attention should also be paid to the quartz content lower than in the case of kaolin, which may result in better reactivity in an alkaline environment, and thus achieving better strength parameters for samples obtained under the analogous conditions.

Figure 2 presents the mid-infrared absorption spectra of kaolin and halloysite (marked as $\mathbf{K}$ and $\mathbf{H}$, respectively) and their calcination products (MK and $\mathbf{M H})$. The strong similarity between the spectra of the samples of kaolin and halloysite can be observed due to the structural similarity of both materials. The bands in the range of $1100-400 \mathrm{~cm}^{-1}$ are associated with the aluminosilicate structure of the material, and come from the vibrations of the $\mathrm{Si}-\mathrm{O}-\mathrm{Si}(\mathrm{Al})$ bridges. The band at $913 \mathrm{~cm}^{-1}$ is characteristic of the kaolinite structure, and comes from $\mathrm{Al}-\mathrm{OH}$ stretching vibrations in the octahedral layer. The band at $695 \mathrm{~cm}^{-1}$, in turn, comes from the vibrations of the Al-O bond for aluminum in the octahedral position. In the spectra of all samples, a characteristic doublet of bands at about 800 and $780 \mathrm{~cm}^{-1}$ can also be seen, indicating the presence of quartz.

The spectra of the materials after the calcination are clearly changed. The bands derived from the water and the $\mathrm{OH}$ groups disappear, which is caused by the dehydroxylation process. Another difference is the increase in FWHM bands derived from $\mathrm{Si}-\mathrm{O}$ and $\mathrm{Al}-\mathrm{O}$ bond vibrations. For the samples of the starting materials, FWHM is small, which means that they had a crystal structure, while in the spectrum of the materials after the heat treatment, they are characterized by a larger FWHM, which indicates a reduced degree of structure ordering. The characteristic band, which indicated the presence of aluminum in the octahedral position (band at $913 \mathrm{~cm}^{-1}$ ) also disappeared, which indicates that a spatial amorphous aluminosilicate structure was obtained. 

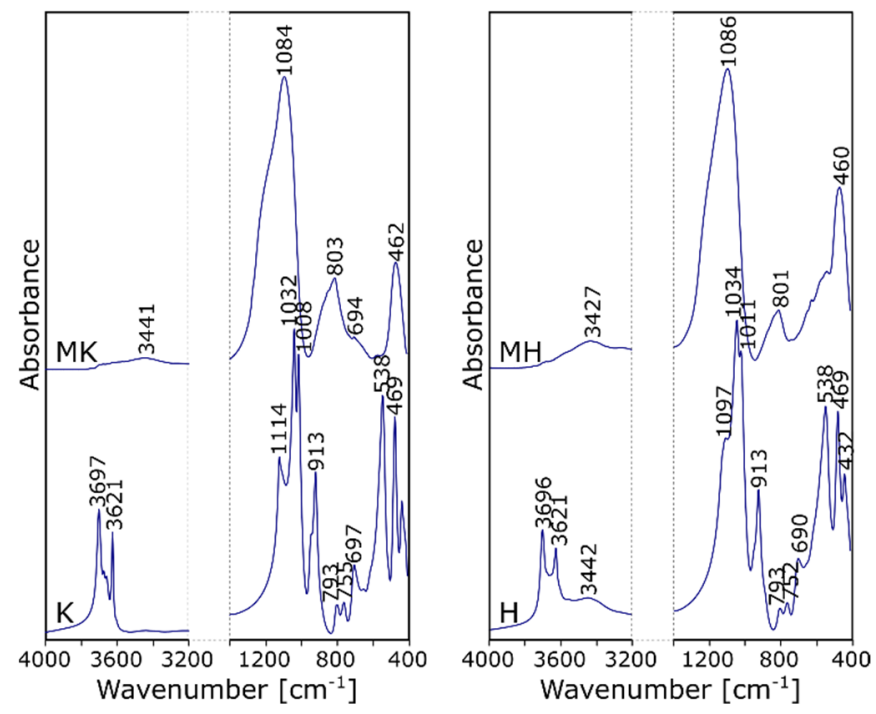

Figure 2. The mid-infrared (MIR) spectra of initial clays (K= kaolin (left) and $\mathbf{H}=$ halloysite (right)) and clays after the calcination at $700{ }^{\circ} \mathrm{C}(\mathbf{M K}=$ metakaolin (left $)$ and $\mathbf{M H}=$ metahalloysite (right) $)$.

\subsection{Characterization of Alkali-Activated Clays}

Zeolite-geopolymer hybrid bulk materials can be obtained using a thermal activated kaolinitic clay. Due to the chemical composition of metakaolin $(\mathrm{Si} / \mathrm{Al}=1)$, the most expected crystalline phase is zeolite A [12], although the appearance of sodalite is not excluded [16].

Figure 3 shows the XRD patterns of the materials obtained as the result of an alkaline activation of both metakaolin (Figure 3a) and metahalloysite (Figure 3b). The analysis of the phase composition showed the presence of quartz (in all samples) and hematite (only in the series based on halloysite). Both mentioned phases were present in the starting material (Figure 1), and did not degrade in the discussed process.

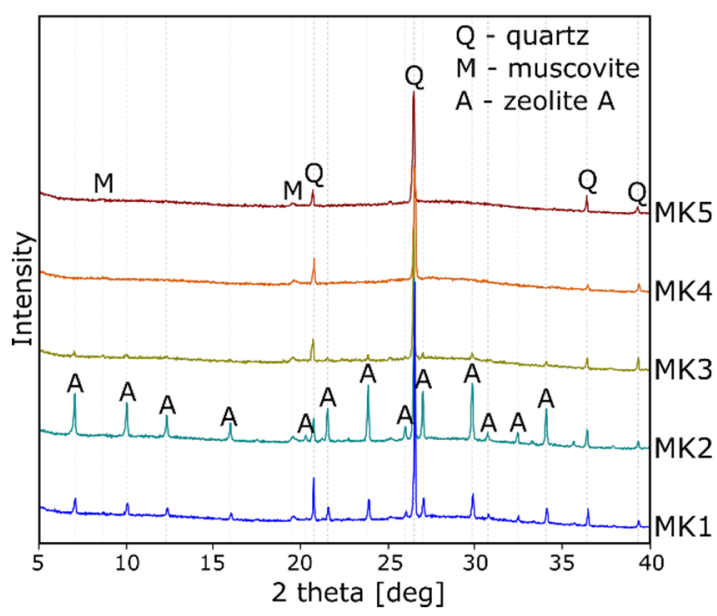

(a)

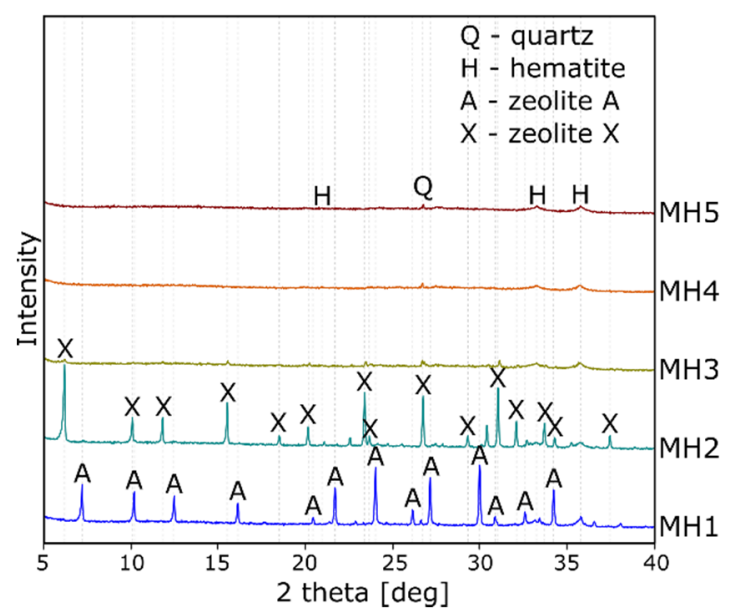

(b)

Figure 3. The XRD patterns of alkali-activated: (a) metakaolin; (b) metahalloysite.

As expected, zeolite A was formed as the result of activation with the highest sodium solution content (MK1 and MH1 samples). Interestingly, in the case of metakaolin (Figure 3a), the activation with the solution with a slightly lower Na/Si ratio (comparing MK1 and MK2) gave the greater amounts of zeolite A. The probable reason was the increased proportion of silicon in the solution in the first 
stages of the geopolymerization process $[17,18]$, which promoted the condensation of tetrahedra into the double-6-ring units, characteristic for LTA structures. In the case of halloysite (MH2), zeolite X was formed under the same conditions. The literature data indicate [1] that this zeolite can be obtained using a longer synthesis time, or in reaction systems with a higher silicon content. It can therefore be assumed, that either the metahalloysite dissolved faster than the metakaolin, or the halloysite contained more silicon in the active phase (despite the similar silicon content in both raw materials (Table 1), metakaolin contained inert quartz (Figure 1)). In the systems with higher silicon content (MK3-MK5 and MH3-MH5), zeolite phases were not formed.

The presence of zeolite phase was confirmed by the SEM observations. The selected results are shown in Figures 4 and 5. Especially in the samples containing zeolite A (MK2; Figure 4a), the cubic crystallites surrounded and joined with a layer of amorphous phase were visible. Zeolite $X$ obtained in the analogous conditions had less developed morphology (MH2, Figure 5a), hence its identification was difficult [16].

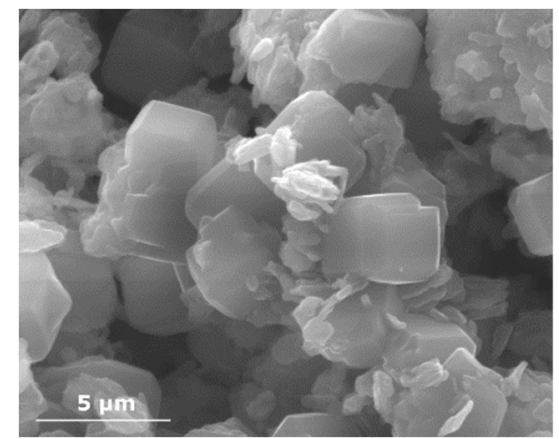

(a)

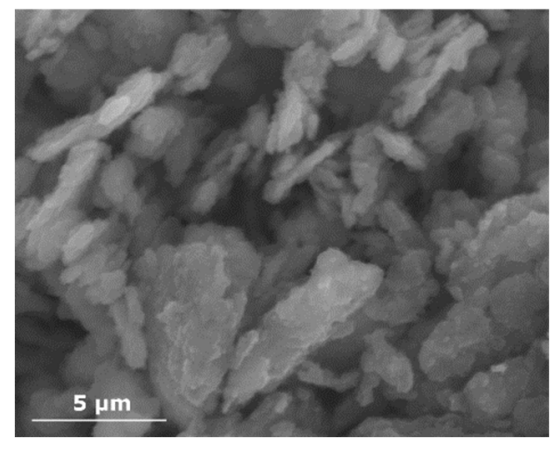

(b)

Figure 4. The microstructure of metakaolin-based composites: (a) MK2; (b) MK5.

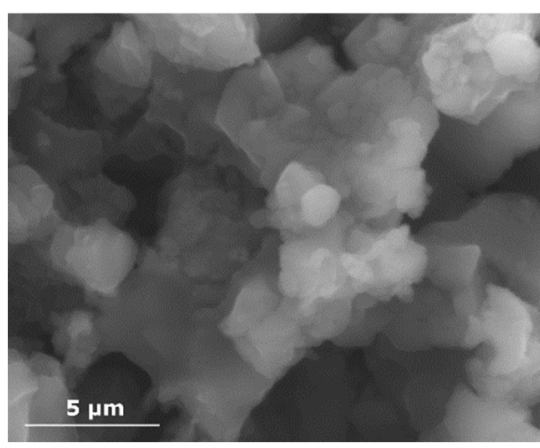

(a)

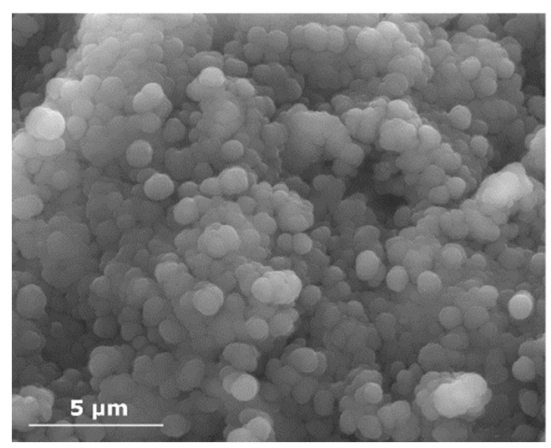

(b)

Figure 5. The microstructure of metahalloysite-based composites: (a) MH2; (b) MH5.

The higher reactivity of metahalloysite compared to metakaolin was demonstrated by the analysis of samples obtained with the higher proportion of water glass in the activating solution. By comparing the microstructure of MK5 (Figure 4b) and MH5 (Figure 5b) samples, it could be easily seen that, while in the case of the sample based on metakaolin (MK5), the low ordered amorphous phase was visible, the sample based on metahalloysite (MH5) was characterized by a microstructure typical for the N-(A)-S-H phase [19].

In the MIR spectra (Figure 6) the bands due to the characteristic vibrations of bonds observed in both types of oxygen bridges, $\mathrm{Si}-\mathrm{O}-\mathrm{Si}$ and $\mathrm{Si}-\mathrm{O}-\mathrm{Al}$, were assigned. These bridges constitute basic structural units, forming tetrahedral geopolymer chains. It was found that the slag composition influences the presence of the bands connected with the phases formed during the hydration in the 
MIR spectra. Additionally, significant effect of amorphous phases share on the spectra shape was established. Based on IR spectra, it was also possible to determine the influence of the activator type on the products formed.

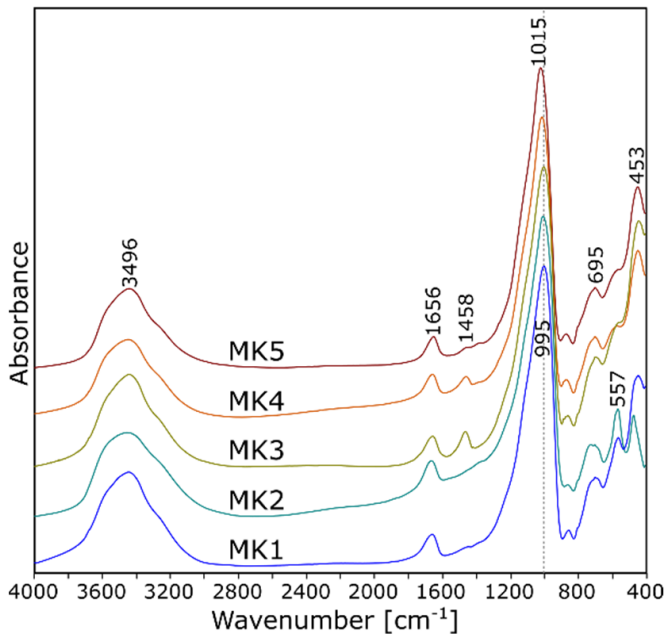

(a)

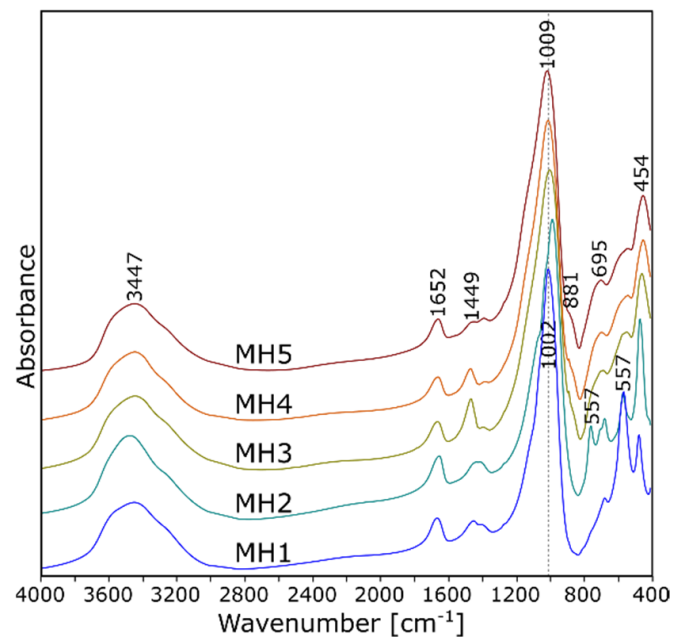

(b)

Figure 6. The MIR spectra of alkali-activated: (a) metakaolin; (b) metahalloysite.

The geopolymerization of alkali-activated metakaolin/metahalloysite (MK/MH) was indicated by the bands corresponding to vibrations of $\mathrm{Si}-\mathrm{O}-\mathrm{Si}(\mathrm{Al})$ at $1200-950 \mathrm{~cm}^{-1}\left(v_{a s}\right)$ and at $750-650 \mathrm{~cm}^{-1}$ $\left(v_{s}\right)$. Their presence in the IR spectra is due to the aluminosilicate character of the structure. These bands do not differ significantly from each other, however, the fact that the envelope in this range is a superposition of several bands should be kept in mind.

First, the slight shift of the most intense band located at about $1000 \mathrm{~cm}^{-1}$ with the increasing amount of water glass can be observed. On the one hand, the reason may be the increasing share of silica in the structure. On the other hand, the degree of structure polymerization can be increased, which would explain the systematic increase in the compressive strength of the MK1-MK5 samples, and which agrees well with the microscopic observations. The analogous conclusions can be drawn by interpreting the spectra of the series of samples based on metahalloysite (MH1-MH5). This observation agrees with our previous conclusions [18].

The significant differences in the IR spectra of the MK1 and MK2 samples are visible in the so-called pseudolattice range, $800-550 \mathrm{~cm}^{-1}$, in which the vibrations of the over-tetrahedral structural units of the zeolite framework can be visible. Especially, characteristic is the band at $557 \mathrm{~cm}^{-1}$, which is connected with the vibrations realized in the zeolite A structure. In turn, the spectrum of the sample MH2 shows two bands characteristic for the faujasite-type structure (zeolite X).

The carbonate group bands were identified at about 1450 and $880 \mathrm{~cm}^{-1}$, as they may be the result of the carbonation of N-(A)-S-H or other sodium compounds, or an unreacted alkali-activator. The interesting observation is the fact that the presence of zeolites in the geopolymer structure inhibits the carbonation process. In this case, sodium was probably bound in the zeolite structure, and there was no free $\mathrm{OH}$ groups that could be involved in the carbonation. On the other hand, the intensity of this band decreased as the sodium content in the reaction systems decreased (hence the disappearance of this band in the spectra of the MH5 sample, obtained by activation with the solution with the lowest sodium content).

The bulk density and compressive strength of the geopolymer samples after 28 days of maturation were determined. The results are shown in Figure 7. Generally, the strength achieved by geopolymers based on clay minerals is relatively low compared to materials based on fly ash or blast furnace waste [20]. In the case of this work, these values did not exceed $12 \mathrm{MPa}$. The highest compressive 
strength values were achieved for the samples MK5/MH5. This is in line with the literature data [21], which indicates that the higher the silicon content in the activator, the higher the strength parameters. It is related to the content of the amorphous phase, that is, the higher the glassy content, the more visually homogenous gel structure (Figures 4 and 5), which have possibly contributed to its high strength after the activation.

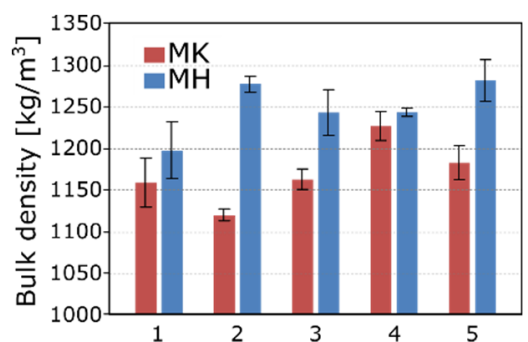

(a)

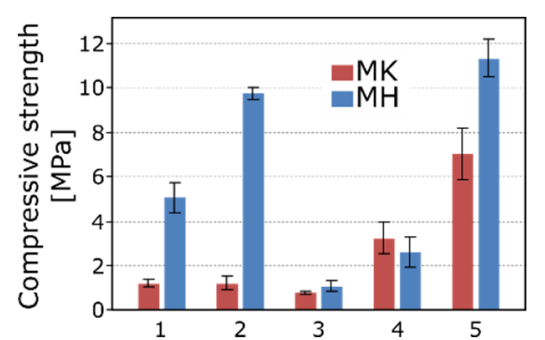

(b)

Figure 7. The physical and mechanical properties of the obtained samples: (a) bulk density; (b) compressive strength.

What is surprising is the high strength of the samples in which zeolite phases were found. Two factors related to the zeolite presence in a geopolymer matrix affect the compressive strength, where one is the amount of zeolites, and the second is the zeolite crystallite size. Their growth causes the decrease in the compressive strength of the composite [2]. The relatively high strength of the obtained samples with zeolites suggest that these factors are at the levels which can be borne by a geopolymer matrix without causing its weakening.

When comparing the two raw materials used, it can be stated that the samples based on metahalloysite were characterized by a higher apparent density, and thus a higher compressive strength. The obtained better strength values may have resulted from the abovementioned absence of quartz in the phase composition of this raw material, as well as from the greater reactivity of metahalloysite compared to metakaolin, which could have affected the formation of phases with the higher structural density. This was confirmed by both the microscopic observations (Figures 4 and 5), and also in the analysis of the infrared spectra (the higher positions of the band originating from $\mathrm{Si}-\mathrm{O}-\mathrm{Si}(\mathrm{Al}$ ) bridges with similar raw material compositions; (Figure 6)).

A significant difference in the iron content of the compared raw materials (Table 2) can be controversial. The role of iron in the geopolymerization process is widely discussed [22-24]. It is generally accepted that the contribution of iron oxide inhibited the geopolymer formation, and it is necessary to control the content of $\mathrm{Fe}_{2} \mathrm{O}_{3}$ to enhance the physical characteristics of geopolymer paste [22]. The distribution of iron in geopolymers made with iron-rich precursors has been also investigated $[23,24]$. The authors agree that iron $\left(\mathrm{Fe}^{3+}\right)$ occupies primarily octahedral positions. However, information can be found that the coordinated $\mathrm{Fe}^{3+}$ replaced $\mathrm{Al}^{3+}$ in the aluminosilicate structure of the geopolymer [24]. On the other hand, some observation suggests the replacement of $\mathrm{Al}^{3+}$ by $\mathrm{Fe}^{3+}$ in octahedral sites most likely within the kaolinite phase, which indicate that iron is not necessarily deleterious to geopolymer formation, as has sometimes been suggested [23].

It was observed that the optimal composition of geopolymer based on fly ash and red mud $\left(\mathrm{Fe}_{2} \mathrm{O}_{3}\right.$ content $=33.9 \mathrm{wt} . \%$ ) was at a weight ratio of 50/50 that gave higher compressive strength than at any other ratio [24]. Geopolymers based on fly ash with a high content of iron oxide (48.8 wt.\%) exhibited better heat resistance than Portland cement concrete [25]. Also, a high iron oxide (31.1 wt.\%) in fly ash has no negative effect on the strength development of geopolymer [26]. Based on the results described in this paper, it is impossible to clearly assess the role of iron in the formation of the geopolymer structure. Although MH contains much higher amounts of iron (Table 2), it is mainly in the form of hematite (Figure 1), and in this form it can also be found in the material after activation (Figure 3). In 
addition, composites based on MH have a higher compressive strength, which is due to the higher degree of structure polymerization observed both in FT-IR and SEM analysis.

\section{Conclusions}

The aim of this study was to determine the effect of the type and concentration of an activator on the structure and properties of the alkali-activated metakaolin and metahalloysite. Therefore, the first stage of the work was based on the obtaining of the metakaolin and metahalloysite phases as a result of the calcination of the starting materials, kaolin and halloysite, respectively. The obtaining of the reactive phases with a similar structure was confirmed by the analysis of the XRD and IR results. The chemical and phase composition analysis confirmed that both of the starting materials are mainly in the amorphous aluminosilicate phase.

The next stage of the work was an attempt to alkali-activate the previously obtained metakaolin and metahalloysite. A number of activation solutions based on sodium hydroxide and sodium silicate were used. The structure and properties of the resulting geopolymer binders depend on both the type of starting material used, and the type of activator. The activation carried out with sodium hydroxide alone, or with a small addition of water glass, causes the formation of zeolite phases, regardless of the starting material used. The alkaline activation with a solution with a higher proportion of silicon did not give crystalline phases, but only an amorphous N-(A)-S-H phase.

The bulk density and compressive strength were determined. The obtained strength values were in the range of 0.7-7.1 MPa for metakaolin, and in the range of 1.1-11.3 MPa for metahalloysite. The geopolymers based on metahalloysite had better strength results, which was probably due to their higher bulk density. A higher density, and thus better strength parameters, were probably the result of the better reactivity of metahalloysite compared to metakaolin.

Zeolites are known for their ability to immobilize heavy metal ions. Although the resulting materials did not obtain the strength parameters valuable for construction, subsequent tests may prove to be attractive materials for neutralizing hazardous waste and water treatment.

Author Contributions: Conceptualization, M.K.; sample preparation, O.B.; measurement, O.B. and P.R.; data curation, O.B. and M.K; writing-original draft preparation, M.K., P.R. and P.F.; writing—review and editing, P.R. and P.F.; project administration, M.K.; funding acquisition, W.M. All authors have read and agreed to the published version of the manuscript.

Funding: This work was financially supported by The National Science Centre Poland under grant no. 2018/31/B/ST8/03109.

Conflicts of Interest: The authors declare no conflict of interest.

\section{References}

1. Breck, D.W. Zeolite Molecular Sieves: Structure, Chemistry, and Use; John Wiley and Sons: Hoboken, NJ, USA, 1974.

2. Rożek, P.; Król, M.; Mozgawa, W. Geopolymer-zeolite composites: A review. J. Clean. Prod. 2019, 230, 557-579. [CrossRef]

3. Takeda, H.; Hashimoto, S.; Yokoyama, H.; Honda, S.; Iwamoto, Y. Characterization of zeolite in zeolite-geopolymer hybrid bulk materials derived from kaolinitic clays. Materials 2013, 6, 1767-1778. [CrossRef] [PubMed]

4. Papa, E.; Medri, V.; Amari, S.; Benito, P.; Vaccari, A.; Landi, E. Zeolite-geopolymer composite materials: Production and characterization. J. Clean. Prod. 2018, 171, 76-84. [CrossRef]

5. Krisnandi, Y.K.; Saragi, I.R.; Sihombing, R.; Ekananda, R.; Sari, I.P.; Griffith, B.E.; Hanna, J.V. Synthesis and characterization of crystalline NaY-Zeolite from Belitung Kaolin as catalyst for n-Hexadecane cracking. Crystals 2019, 9, 404. [CrossRef]

6. Pereira, P.M.; Ferreira, B.F.; Oliveira, N.P.; Nassar, E.J.; Ciuffi, K.J.; Vicente, M.A.; Trujillano, R.; Rives, V.; Gil, A.; Korili, S.; et al. Synthesis of zeolite A from metakaolin and its application in the adsorption of cationic dyes. Appl. Sci. 2018, 8, 608. [CrossRef] 
7. Lima-de-Faria, J. Structural Classification of Minerals; Springer: New York, NY, USA, 2003; Volume 2, p. 18.

8. Hillier, S.; Ryan, P.C. Identification of halloysite $(7 \AA)$ by ethylene glycol solvation: The 'MacEwan effect. Clay Miner. 2002, 37, 487-496. [CrossRef]

9. Slaty, F.; Khoury, H.; Wastiels, J.; Rahier, H. Characterization of alkali activated kaolinitic clay. Appl. Clay Sci. 2013, 75-76, 120-125. [CrossRef]

10. Wang, Q.; Zhang, J.; Wang, A. Alkali activation of halloysite for adsorption and release of ofloxacin. Appl. Surf. Sci. 2013, 287, 54-61. [CrossRef]

11. San Cristóbal, A.G.; Castelló, R.; Martín Luengo, M.A.; Vizcayno, C. Zeolites prepared from calcined and mechanically modified kaolins. A comparative study. Appl. Clay Sci. 2010, 49, 239-246. [CrossRef]

12. Król, M.; Rożek, P. The effect of calcination temperature on the metakaolin structure for the synthesis of zeolites. Clay Miner. 2019, 53, 657-663. [CrossRef]

13. Giese, R.F. Kaolin group minerals. In Encyclopedia of Sediments and Sedimentary Rocks; Middleton, G.V., Church, M.J., Coniglio, M., Hardie, L.A., Longstaffe, F.J., Eds.; Springer: Dordrecht, The Netherlands, 2003; pp. 398-400.

14. Velde, B. 1:1 dioctahedral clays (kaolinite, dickite, nacrite halloysite). In Introduction to Clay Minerals-Chemistry, Origins, Uses and Environmental Significance; Crowley, S., Ed.; Chapman and Hall: London, UK, 1992; pp. 79-80.

15. Brindley, G.W.; Nakahira, M. Kinetics of dehydroxylation of kaolinite and halloysite. J. Am. Ceram. Soc. 1957, 40, 346-350. [CrossRef]

16. Król, M.; Minkiewicz, J.; Mozgawa, W. IR spectroscopy studies of zeolites in geopolymeric materials derived from kaolinite. J. Mol. Struct. 2016, 1126, 200-206. [CrossRef]

17. Duxson, P.; Fernández-Jiménez, A.; Provis, J.L.; Lukey, G.C.; Palomo, A.; Van Deventer, J.S.J. Geopolymer technology: The current state of the art. J. Mater. Sci. 2007, 42, 2917-2933. [CrossRef]

18. Król, M.; Rożek, P.; Chlebda, D.; Mozgawa, W. ATR/FT-IR studies of zeolite formation during alkali-activation of metakaolin. Solid State Sci. 2019, 94, 114-119. [CrossRef]

19. Król, M.; Rożek, P.; Mozgawa, W. Preparation and Structure of Geopolymer-Based Alkali-Activated Circulating Fuildized Bed Ash Composite for Removing $\mathrm{Ni}^{2+}$ from Wastewater. In Proceedings of the 12th Pacific Rim Conference on Ceramic and Glass Technology: Ceramic Transactions; Singh, D., Fukushima, M., Kim, Y., Shimamura, K., Imanaka, N., Ohji, T., Amoroso, J., Lanagan, M., Eds.; John Wiley \& Sons: Hoboken, NJ, USA, 2018; Volume 264, pp. 147-154.

20. Abdullah, M.M.A.B.Y.; Liew, M.; Yong, H.C.; Tahir, M.F.M. Clay-Based Materials in Geopolymer Technology. In Cement Based Materials; IntechOpen: Rijeka, Croatia, 2018; pp. 239-264.

21. Prochon, P.; Zhao, Z.; Courard, L.; Piotrowski, T.; Michel, F.; Garbacz, A. Influence of Activators on Mechanical Properties of Modified Fly Ash Based Geopolymer Mortars. Materials 2020, 13, 1033. [CrossRef] [PubMed]

22. Choi, S.C.; Lee, W.K. Effect of $\mathrm{Fe}_{2} \mathrm{O}_{3}$ on the physical property of geopolymer paste. Adv. Mater. Res. 2012, 586, 126-129. [CrossRef]

23. Lemougna, P.N.; MacKenzie, K.J.D.; Jameson, G.N.L.; Rahier, H.; Chinje Melo, U.F. The role of iron in the formation of inorganic polymers (geopolymers) from volcanic ash: A ${ }^{57} \mathrm{Fe}$ Mössbauer spectroscopy study. J. Mater. Sci. 2013, 48, 5280-5286. [CrossRef]

24. Hu, Y.; Liang, S.; Yang, J.; Chen, Y.; Ye, N.; Ke, Y.; Tao, S.; Xiao, K.; Hu, J.; Hou, H.; et al. Role of Fe species in geopolymer synthesized from alkali-thermal pretreated Fe-rich Bayer red mud. Constr. Build. Mater. 2019, 200, 398-407. [CrossRef]

25. You, S.; Ho, S.W.; Li, T.; Maneerung, T.; Wang, C.H. Techno-economic analysis of geopolymer production from the coal fly ash with high iron oxide and calcium oxide contents. J. Hazard. Mater. 2019, 361, 237-244. [CrossRef] [PubMed]

26. Kumar, S.; Djobo, J.N.Y.; Kumar, A.; Kumar, S. Geopolymerization behavior of fine iron-rich fraction of brown fly ash. J. Build. Eng. 2016, 8, 172-178. [CrossRef]

(C) 2020 by the authors. Licensee MDPI, Basel, Switzerland. This article is an open access article distributed under the terms and conditions of the Creative Commons Attribution (CC BY) license (http://creativecommons.org/licenses/by/4.0/). 